\title{
Influence of zeaxanthin on quantum yield of photosynthesis of Synechococcus clone WH7803 $(\mathrm{DC} 2)^{*}$
}

\author{
Robert R. Bidigare ${ }^{1}$, Oscar Schofield ${ }^{2}$, Barbara B. Prézelin ${ }^{2}$ \\ ${ }^{1}$ Geochemical and Environmental Research Group, Department of Oceanography, Texas A \& M University, College Station, \\ Texas 77843, USA \\ ${ }^{2}$ Department of Biological Sciences and Marine Science Institute, University of California, Santa Barbara, California 93106 , \\ USA
}

\begin{abstract}
Synechococcus clone WH7803 (DC2) was grown on a 12:12 h light-dark cycle of either blue-green fluorescent, white fluorescent or daylight-filtered tungsten light. Integrated irradiance for each culture was set at $15 \mu$ Ein $\mathrm{m}^{-2} \mathrm{~s}^{-1}$ Subsequent measurements of absorption, pigmentation and carbon action spectra were used to examine wavelength-dependence of photosynthetic quantum yield. Comparison of directly-measured and reconstructed absorption spectra suggests that pigment packaging' effects are minimal in Synechococcus. Spectral quality had a marked effect on pigmentation and quantum yield. Cellular concentrations of chlorophyll $a, \beta$-carotene and phycoerythrin were all $\sim 2$-fold lower in daylight-grown Synechococcus relative to blue-green and white light-grown cells; ratios of $\beta$ carotene-and phycoerythrin-to-chlorophyll a were markedly constant for all 3 illuminations. Blue-green light grown Synechococcus cells had a $\sim 2$-fold higher zeaxanthin content than those grown under white light or daylight illuminations. These results indicate that cellular zeaxanthin content is not an implicit constant and its concentration is dependent on irradiance levels of blue-green light. Zeaxanthin probably serves an important function as a photoprotectant pigment in Synechococcus, and as such. can also produce significant decreases $(20$ to $40 \%)$ in the apparent quantum yield for photosynthesis in the blue-green region of the visible spectrum. In contrast, highest quantum yields were routinely measured between 525 and $650 \mathrm{~nm}$ suggesting that light absorbed by phycobilins (phycoerythrin and phycocyanin) drive the majority of carbon fixation in DC2-like coccoid cyanobacteria. In calculating the spectral quantum yield for natural phytoplankton populations, it is suggested that (1) carbon action spectra be determined under 'enhanced' conditions and (2) photosynthetically absorbed radiation for phytoplankton be estimated using spectral reconstruction techniques where absorption contributions by nonphotosynthetic chromophores are removed from whole cell absorption signatures.
\end{abstract}

\section{INTRODUCTION}

Coccoid marine cyanobacteria (Synechococcus spp.) comprise an abundant and ecologically important group of phototrophs found in coastal and openoceanic waters (for review see Glover 1985). Maximum abundances of Synechococcus spp. range from $\sim 10^{3}$ to $10^{5}$ cells $\mathrm{ml}^{-1}$ and are typically found at depths corresponding to or shallower than the $1 \%$ light level (Murphy \& Haugen 1985, Glover et al. 1986 a, Iturriaga \& Mitchell 1986, Glover et al. 1988a, Iturriaga \& Marra 1988, Prézelin et al. 1989). In general, Synechococcus spp. are more susceptible to photoinhibition than

\footnotetext{
- Biowatt Contribution No. 24
}

eukaryotic ultraplanktonic algae and display $I_{k}$ (intensity of light at which photosynthesis is light-saturated) ranging from 50 to $150 \mu$ Ein $\mathrm{m}^{-2} \mathrm{~s}^{-1}$ (Barlow \& Alberte 1985, Glover et al. 1987, Kana \& Glibert 1987, Prézelin et al. 1989, Boucher, Schofield \& Prézelin unpubl.). Thus, it is not surprising that the highest primary production contributions by Synechococcus spp. occur (1) early in the morning/late in the day: (2) on cloudy days; or (3) at intermediate depths in the water column (Glover et al. 1985, 1986a, Prézelin et al. 1986, 1989). Numerous field studies have documented that Synechococcus spp. account for $\sim 50-95 \%$ of the total daily primary production in open-oceanic waters (Iturriaga \& Mitchell 1986, Iturriaga \& Marra 1988, Prézelin et al. 1989). Synechococcus spp. production has been shown 
to be closely coupled to microzooplankton grazing and therefore is thought to be a significant source of carbon and new nitrogen for higher trophic levels (Glover et al. 1986a, Iturriaga \& Mitchell 1986, Glover et al. 1988b).

Synechococcus spp. are chromatically suited for efficient photosynthesis and growth at the blue-green to green wavelengths of light which predominate in the upper water column (Wood 1985, Glover et al. 1986b, Glover et al. 1987, Prézelin et al. 1989, Boucher et al. unpubl.). The major pigments identified in Synechococcus spp. include chlorophyll a, zeaxanthin, phycocyanin (PC), phycoerythrin (PE) and $\beta$-carotene (Alberte et al. 1984, Guillard et al. 1985, Wood et al. 1985). Three subgroups of Synechococcus spp. have been designated based on phycobilin pigmentation: (1) PE-rich containing phycoerythrobilin, phycourobilin and phycocyanobilin chromophores (Type I); (2) PErich containing phycoerythrobilin and phycocyanobilin chromophores (Type II); and (3) PE-lacking containing phycocyanobilin chromophores. The latter 2 subgroups are inefficient in absorbing blue-green light for photosynthesis and are primarily resticted to neritic waters (Glover 1985, Wood 1985, Olson et al. 1988). The first subgroup, Type I Synechococcus spp., can be further subdivided depending on the relative contents phycoerythrobilin ( $\mathrm{PEB}, \lambda_{\max }=\sim 550 \mathrm{~nm}$ ) and phycourobilin (PUB, $\lambda_{\max }=\sim 495 \mathrm{~nm}$ ). PEB-rich (e.g. WH7803, Kilpatrick 1985) and PUB-rich (e.g. WH8103, Ong et al. 1984) Synechococcus spp. are typically found in green coastal and blue open-oceanic waters, respectively (Vernet et al. 1986, Campbell \& Iturriaga 1988, Glover et al. 1988a, Olson et al. 1988, Bidigare et al. 1989).

The ecological importance of Synechococcus spp. in the marine environment has promped investigations into the factors which control the carbon fixation rates of these ultraplanktonic algae. Recent studies utilizing carbon-based action spectra have shown that marine cyanobacteria display conspicuously low $\alpha$ (mgC $\left.\mathrm{mgChl}^{-1} \cdot \mathrm{h}^{-1}\left(\mu \text { Ein } \mathrm{m}^{-2} \mathrm{~s}^{-1}\right)^{-1}\right)$ and quantum yield ( $\mathrm{molC} \mathrm{Ein}^{-1}$ ) values within the blue waveband where chlorophyll a absorbs (Lewis et al. 1986, Lewis et al. 1988, Boucher et al. unpubl.). Lewis et al. (1988) invoked 2 possible mechanisms to explain these observations: (1) an energy imbalance in light distribution between PSI and PSII (i.e a restricted Emerson enhancement effect) and (2) the absorption of light by pigments which are inefficient in photosynthetic energy transfer. The first mechanism was recently investigated by Boucher et al. (unpubl.) using PEB-rich Synechococcus sp. clone WH7803 (DC2). Most interestingly, blue-green light enhanced carbon action spectra gave 3 -fold higher quantum yield values for the blue-absorption peak of chlorophyll a than those determined from unenhanced spectra. But even with enhanced carbon spectra, the photosynthetic efficiency of blue light absorption was lower than that measured for phycoerythrin and phycocyanin light absorption at longer wavebands (Boucher et al. unpubl.). It is here postulated that zeaxanthin $\left(\lambda_{\max }=\sim 460 \mathrm{~nm}\right.$ ), being inefficient in photosynthetic energy transfer in Synechococcus (Kana et al. 1988, Boucher et al. unpubl.), is a potential agent for lowering quantum yield in the blue region of the visible spectrum (where it can dominate cell absorption).

The primary goal of the present study is to assess quantitatively the influence of zeaxanthin on estimates of the apparent photosynthetic quantum yield of marine Synechococcus clone WH7803 (DC 2). Toward this objective, measurements of wavelength-dependent alpha $[\alpha(\lambda)]$, absorption $[A(\lambda)]$ and cellular pigmentation were performed on batch cultures grown under 3 different light qualities of equal integrated growth irradiance. The major light absorbing components of Synechococcus were identified using spectral reconstruction techniques. These results were used to examine the wavelength-dependence of photosynthetic quantum yield $[\phi(\lambda)]$ in relation to cellular zeaxanthin concentrations and the spectral quality of growth irradiance

\section{MATERIALS AND METHODS}

Culture. Unialgal batch cultures of Synechococcus Clone WH 7803 (DC 2) were grown on a $12: 12$ h lightdark cycle of either (1) blue-green fluorescent light (GE F20T12-CW, 20 Watt; Lee 118 transparent blue photographic filter) or (2) white fluorescent light (GE F20T12-CW, 20 Watt) or (3) daylight provided by a tungsten lamp (filtered with a Cool Lux (LC-7000) coated pyrex photographic filter). Procedures for measuring the spectral output of growth irradiances have been previously described (Prézelin et al. 1989). The integrated irradiance for each culture was set at $15 \mu$ Ein $\mathrm{m}^{-2} \mathrm{~s}^{-1}$ (Fig. 1). Growth was sustained in a modified f/2 medium (Guillard \& Ryther 1962), where inorganic nitrate was replaced by a mixture of $0.3 \mathrm{ml} \mathrm{l}^{-1}$ each of $15 \% \mathrm{NaNO}_{3}$ and $15 \% \mathrm{NH}_{4} \mathrm{Cl}_{\text {, the metal mix- }}$ ture lacked $\mathrm{CuSO}_{4}$ and the EDTA was increased to $0.005 \%$ in the $1.26 \%$ ferric sequestrene (Guillard \& Keller pers. comm.).

Cell enumeration. Cell densities of the Synechococcus cultures were determined by epifluorescence microscopy (Glover et al. 1986a).

Pigment analyses. Ten ml aliquots of culture were filtered onto $0.4 \mu \mathrm{m}$ Nuclepore filters and extracted in $5 \mathrm{ml} 90 \%$ acetone for $48 \mathrm{~h}\left(-20^{\circ} \mathrm{C}\right)$ to ensure good extraction efficiencies. Following extraction, pigment samples were centrifuged for 5 min to remove cellular debris. All filters yielded pink cell residues after extraction. 


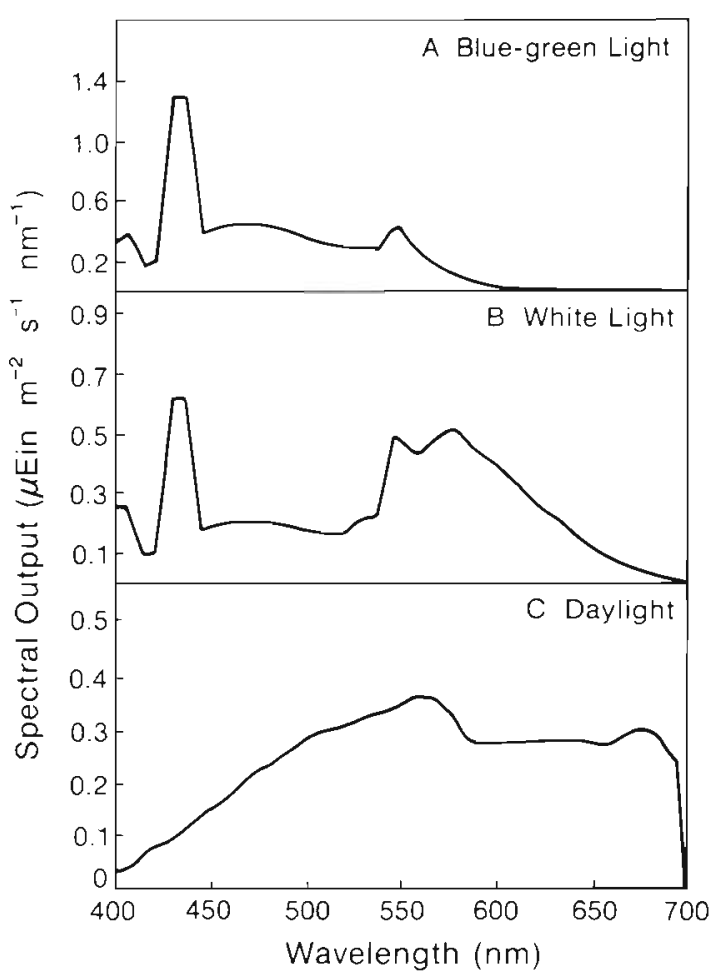

Fig. 1. Spectral distribution of the 3 growth illuminations used for culturing Synechococcus clone 7803 (DC2). The integrated growth irradiance for each light quality equaled $15 \mu \mathrm{Ein} \mathrm{m}^{-2}$ $\mathrm{s}^{-1}$ (note that cells grown under blue-green light received a -2 -fold higher flux of blue photons than those grown under white light and daylight)

Acetone-extractable pigments were analyzed in triplicate by reverse-phase high-performance liquid chromatography (Bidigare 1989). Pigments were separated using a Spectra-Physics Model SP 8700 liquid chromatograph equipped with a Radial-PAK $\mathrm{C}_{18}$ column $(0.8 \times 10 \mathrm{~cm}, 5 \mu \mathrm{m}$ particle size; Waters Chrom. Div.) at a flow rate of $6 \mathrm{ml} \mathrm{min}^{-1}$. Prior to injection, $1 \mathrm{ml}$ aliquots of the standards and Synechococcus extracts were mixed separately with $300 \mu \mathrm{l}$ of ion-pairing solution $115 \mathrm{~g}$ of tetrabutylammonium acetate and $77 \mathrm{~g}$ ammonium acetate diluted to $1 \mathrm{l}$ with distilled water;
Mantoura \& Llewellyn 1983). A 2-step solvent program was used to separate the various pigments extracted from Synechococcus. After injection (500 $\mu \mathrm{l}$ sample), mobile phase A $(80: 15: 5$; methanol 'water ion-pairing solution) was ramped to mobile phase B (methanol) over a 12 min period. Mobile phase $B$ was then pumped for $18 \mathrm{~min}$ for a total analysis time of $30 \mathrm{~min}$. Individual peaks were detected and quantified (by area) with a Waters Model 440 Fixed Wavelength Detector $(436 \mathrm{~nm})$ and a Hewlett-Packard Model $3392 \mathrm{~A}$ integrator, respectively. The identities of the peaks obtained from the Synechococcus extracts were determined by comparing their retention times with those of pure standards and extracts prepared from 'standard' plant materials of known pigment composition (Zea mays and Phaeodactylum tricornutum). On-line diode array spectroscopy (HPLC/DAS; 350 to $550 \mathrm{~nm}$ for carotenoids and 400 to $700 \mathrm{~nm}$ for chlorophylls) was performed using a Hewlett Packard Model HP 8451 Diode Array Spectrophotometer to confirm the identities of the carotenoids and chlorophyll a.

Pigment standards were obtained from Sigma Chemical Co. (chlorophyll $a$ and $\beta$-carotene) or purified from Zea mays (zeaxanthin) by thin-layer chromatography (Jeffrey 1981). Concentrations of the pigment standards were determined spectrophotometrically in $1 \mathrm{~cm}$ cuvettes using published extinction coefficients in the appropriate solvent systems (Table 1). Known pigment quantities were injected and resultant peak areas were used to calculate individual standard response factors (ng pigment area ${ }^{-1}$ ). Pigment concentrations (ng pigment $\mathrm{ml}^{-1}$ ) of the Synechococcus extracts were calculated with these response factors and knowledge of the injection volume. Accessory pigment-to-chlorophyll a ratios (weight: weight) were calculated from the pigment concentrations determined for each clone.

Phycoerythrin concentrations were calculated from the difference spectra obtained between measured and reconstructed (chlorophyll a + zeaxanthin $+\beta$-carotene, see below) and an extinction coefficient of $25.5 \mathrm{l} \mathrm{g}^{-1}$ $\mathrm{cm}^{-1}$ (Kilpatrick 1985). Phycocyanin is present in Synechococcus clone WH7803 at relatively low con-

Table 1. Extinction coefficients $\left(\mathrm{g} \mathrm{g}^{-1} \mathrm{~cm}^{-1}\right)$ and wavelength shifts used for producing the in vivo specific absorption coefficients for the major pigments of clone DC2

\begin{tabular}{|c|c|c|c|c|}
\hline Pigment & $\lambda_{\max }$ (solvent) & $E\left(\mathrm{l} \mathrm{g}^{-1} \mathrm{~cm}^{-1}\right)$ & Ref. & $\lambda$ shift \\
\hline Chlorophyll a & $\begin{array}{l}664 \mathrm{~nm}(90 \% \text { acetone }) \\
432 \mathrm{~nm}(90 \% \text { acetone })\end{array}$ & $\begin{array}{c}87.7 \\
-\end{array}$ & $(1)$ & $\begin{array}{l}>550 \mathrm{~nm}:+16 \mathrm{~nm} \\
<550 \mathrm{~nm}:+8 \mathrm{~nm}\end{array}$ \\
\hline Zeaxanthin & $450 \mathrm{~nm}(\mathrm{EtOH})$ & 254.0 & $(2)$ & $>375 \mathrm{~nm}:+12 \mathrm{~nm}$ \\
\hline$\beta$-carotene & $449 \mathrm{~nm}(\mathrm{EtOH})$ & 262.0 & $(2)$ & $>375 \mathrm{~nm}:+13 \mathrm{~nm}$ \\
\hline Phycoerythrin & $547 \mathrm{~nm}$ ( $\mathrm{Pj}$ buffer) & 25.5 & (3) & no shift \\
\hline
\end{tabular}


centrations (Alberte et al. 1984, Wyman et al. 1985) and cellular levels could not be estimated by the methods used in this study.

Carbon action spectra. Carbon action spectra $(\alpha$, mgC mgChl ${ }^{-1} \mathrm{~h}^{-1}\left[\mu \text { Ein } \mathrm{m}^{-2} \mathrm{~s}^{-1}\right]^{-1}$ ) were measured on a spectral photosynthetron (Lewis et al. 1985a) as modified by Boucher et al. (unpubl.). Two identical photosynthetrons were equipped individually with nine 75 Watt Cool Lux FOS 8 tungsten halogen lamps, each centered in a light-tight fitting beneath a $2^{\prime \prime}$ square glass bandpass interference filter (PTR Optics, Waltham, MA and Corning Optics, Hollingston, MA). Thirteen of these experimental slots were fitted with different colored spectral filters, with wavebands centered at 400 to $700 \mathrm{~nm}$ in $25 \mathrm{~nm}$ increments (half-band width $=12.5 \mathrm{~nm}$ ). Above each interference filter, a water-cooled plexiglass chamber was aligned with a light-tight reflecting cone. Within each chamber was a sample holder comprised of 5 copper tubes with inner diameters equivalent to the outer diameter of $20 \mathrm{ml}$ glass vials, the latter being used as incubation containers for carbon uptake measurements. The spectral integrity of the light reaching each sample location was verified with a Li-Cor LI-185B spectroradiometer. Irradiance levels within each sample location were modified by using various combinations of neutral density plexiglass disks between the glass vials and the base of the incubation chambers. Irradiance was measured with a Li-Cor LI-185 A light meter and an attached underwater quantum sensor which fitted into each sample chamber so that light measurements could be made at the chamber base without light leaks from above. Drift in mean irradiance measurements during incubation was $<5 \%$.

In experimental runs, $140 \mathrm{ml}$ of each culture was inoculated with $\mathrm{NaH}^{14} \mathrm{CO}_{3}$ (final activity of $\sim 0.38 \mu \mathrm{Ci}$ $\mathrm{ml}^{-1}$ ) and $1 \mathrm{ml}$ aliquots were dispensed into $20 \mathrm{ml}$ acidwashed glass scintillation vials. One hundred vials were used for the determination of carbon action spectra. Glacial acetic acid:methanol mix (1:30) (GAM) was immdiately added to 4 'time-zero' samples. Remaining vials were placed in the spectral photosynthetrons for $45 \mathrm{~min}$, after which the incubations were terminated with GAM. Samples were heat-dried and $1 \mathrm{ml}$ of double deionized water was added to resolubilize the salts. Nine $\mathrm{ml}$ of Liquiscint scintillation solution was added and the samples were counted on a LKB 1217 Scintillation Counter. Quench was corrected using an internal standard and all samples were corrected for uptake in the 'time-zero' samples. Photosynthetic rates were calculated as described in Strickland \& Parsons (1972). For each waveband, the photosynthetic rate was determined as a linear function. of irradiance (Lewis et al. 1985a). Respiration was assumed to be light-dependent and constant. The wavelength-dependent slope, $\alpha(\lambda)$, was estimated by linear regression and plotted to show \pm one standard error of the estimate (Lewis et al. 1985a).

Absorption measurements. Absorption spectra of unfiltered cell suspensions were measured in $1 \mathrm{~cm}$ quartz cuvettes with a DW-2a spectrophotometer, Opal glass was inserted between the sample/reference cuvettes and the scattering attachment directed $>90 \%$ of the transmitted light to the photomultiplier tube. A $0.4 \mu \mathrm{m}$ Nuclepore filtrate prepared from the cell suspensions was used as the reference. The spectra presented here represent cell suspensions where self-shading was minimized, evidenced by the linerity of the dilution series and the added criterion that all cell suspensions have an optical thickness of $<0.05 \mathrm{~cm}^{-1}$ (Morel et al. 1987). For the purpose of calculating spectral quantum yield, the directly-measured spectra were transformed into chlorophyll-specific absorption coefficients $\left(a_{c}[\lambda], \mathrm{m}^{2} \mathrm{mg}^{-1} \mathrm{Chl}\right.$, base e) by dividing the absorption spectra by the volume-based chlorophyll a concentrations.

Spectral reconstruction. Absorption spectra $(A(\lambda))$ of Synechococcus cultures were reconstructed from knowledge of the in vivo spectral absorbtion coefficients of the individual pigments $\left(\mathrm{a}_{1}(\lambda), \mathrm{m}^{2} \mathrm{mg}^{-1}\right.$, base e) and their volume-based concentrations $\left(\mathrm{C}_{1}, \mathrm{mg} \mathrm{m}^{-3}\right)$ (cf. Mann \& Myers 1968, Bidigare et al. 1987):

$$
A(\lambda)=\sum a_{1}(\lambda) \cdot C_{i}
$$

Absorption spectra were obtained from pure standards, wavelength-shifted to match their in vivo maxima, and normalized to the $E_{i \max }$ values given in Table 1 . The individual pigment-specific absorption coefficients $\left(\mathrm{m}^{2}\right.$ $\mathrm{mg}^{-1}$ pigment, base el used for spectral reconstruction are shown in Fig. 2.

Photosynthetic quantum yield. Spectral quantum yields $\left(\phi(\lambda), \operatorname{molC} \operatorname{Ein}^{-1}\right)$ values were calculated by

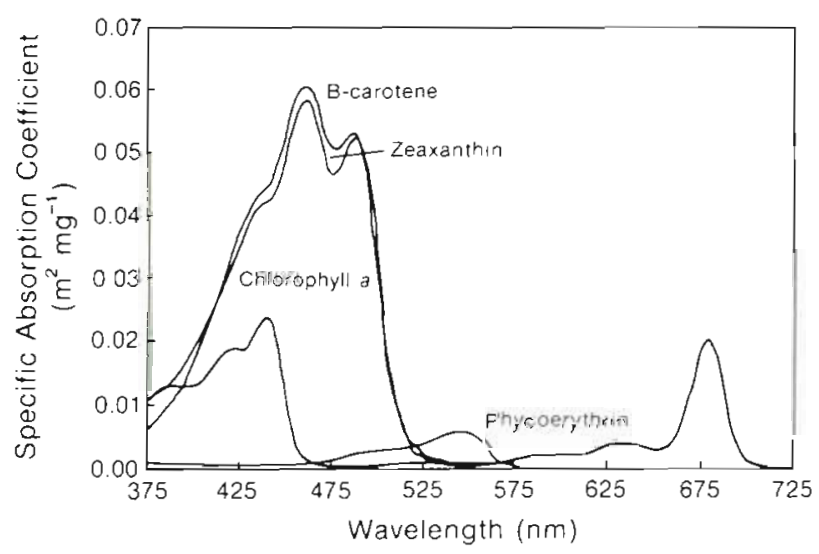

Fig. 2. In vivo pigment-specific absorption coefficients $\left(\mathrm{m}^{2}\right.$ $\mathrm{mg}^{-1}$ pigment, base e) used for the reconstruction of Synechococcus absorption spectra 
dividing the carbon action spectra by the chlorophyllspecific absorption coefficients as follows (Lewis et al. 1985b, Boucher et al. unpubl.).

$$
\phi(\lambda)=\frac{\alpha(\lambda)}{a_{c}(\lambda)}
$$

\section{RESULTS}

\section{Pigmentation}

Volume-based pigment concentrations and cell count data (Table 2) were used to calculate cell-based pigment concentrations for Synechococcus clone WH7803. Cellular concentrations of chlorophyll $a, \beta-$ carotene and phycoerythrin were all $\sim 2$-fold lower in daylight grown Synechococcus relative to blue-green and white light grown cells. For chlorophyll $a$ and phycoerythrin, values ranged from 6.6 to 14.8 and 51.3 to $109.4 \mathrm{fg}$ pigment cell ${ }^{-1}$, respectively (Table 3 ). While these values are generally higher than those reported for Synechococcus clone WH7803 grown under continuous illumination provided by cool-white fluorescent lamps (Cuhel \& Waterbury 1984, Barlow \& Alberte 1985, Kilpatrick 1985, Kana \& Clibert 1987), they are in good agreement with cellular concentrations measured for natural populations of Synechococcus spp. sampled near the base of the euphotic zone. Glover et al. (1988a) found that the chlorophyll $a$ and phycoerythrin concentrations of Synechococcus spp. sampled in the Sargasso
Sea increased with optical depth, and values within in the euphotic zone ranged from $\sim 4$ to 24 and $\sim 20$ to $100 \mathrm{fg}$ pigment cell ${ }^{-1}$, respectively.

Ratios of $\beta$-carotene- and phycoerythrin-tochlorophyll a $(\mathrm{w}: \mathrm{w})$ were markedly constant for all 3 growth illuminations, and averaged $0.16 \pm 0.02(n=3)$ and $7.68 \pm 0.72(n=3)$, respectively (Table 3$)$. Bluegreen light grown Synechococcus cells had a $\sim 2$-fold higher zeaxanthin content than those grown under white light or daylight growth illuminations. The corresponding zeaxanthin-to-chlorophyll a ratios calculated for blue-green and daylight grown Synechococcus averaged 0.52 , and were $\sim 2$-fold higher than those calculated for white light grown Synechococcus. These values are in general agreement with the results of Kana et al. (1988) who measured $\beta$-carotene-tochlorophyll $a$ and zeaxanthin-to-chlorophyl a ratios (w: w) of 0.14 and 0.40 , respectively, for Synechococcus clone WH7803 grown under low growth irradiances of white fluorescent light.

\section{Spectral absorption measurements}

Directly-measured absorption values were appreciably higher than those estimated from reconstruction techniques, especially in the blue region of the visible spectrum (Fig. 3). To investigate this discrepancy, as well as estimating phycoerythrin concentrations for each culture condition (see 'Materials and methods'), difference spectra were calculated between directly-

Table 2. Volume-based pigment concentrations and cell count data for Synechococcus clone WH7803 (DC2)

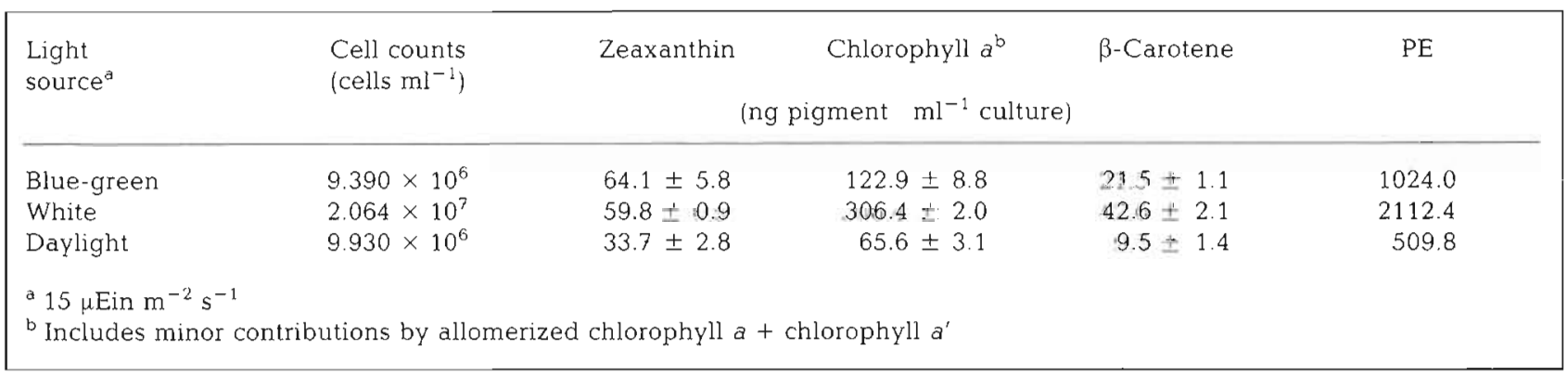

Table 3. Cell-based pigment concentrations and pigment ratios for Synechococcus clone WH7803 (DC2)

\begin{tabular}{|c|c|c|c|c|c|c|c|}
\hline $\begin{array}{l}\text { Light } \\
\text { source }\end{array}$ & Zea. & $\begin{array}{l}\mathrm{Chl} a^{\mathrm{b}} \\
\text { (fg pigment }\end{array}$ & $\begin{array}{l}\beta \text {-Car. } \\
\text { cell }{ }^{-1} \text { ) }\end{array}$ & $\mathrm{PE}$ & Zea.: Chi & $\begin{array}{c}\text { Car. Chl } \\
(w: w)\end{array}$ & PE : Chl \\
\hline Blue-green & 6.8 & 13.1 & 2.3 & 109.4 & 0.52 & 0.18 & 8.35 \\
\hline White & 2.9 & 14.8 & 2.1 & 102.3 & 0.20 & 0.14 & 6.91 \\
\hline Daylight & 3.4 & 6.6 & 1.0 & 51.3 & 0.52 & 0.15 & 7.77 \\
\hline
\end{tabular}



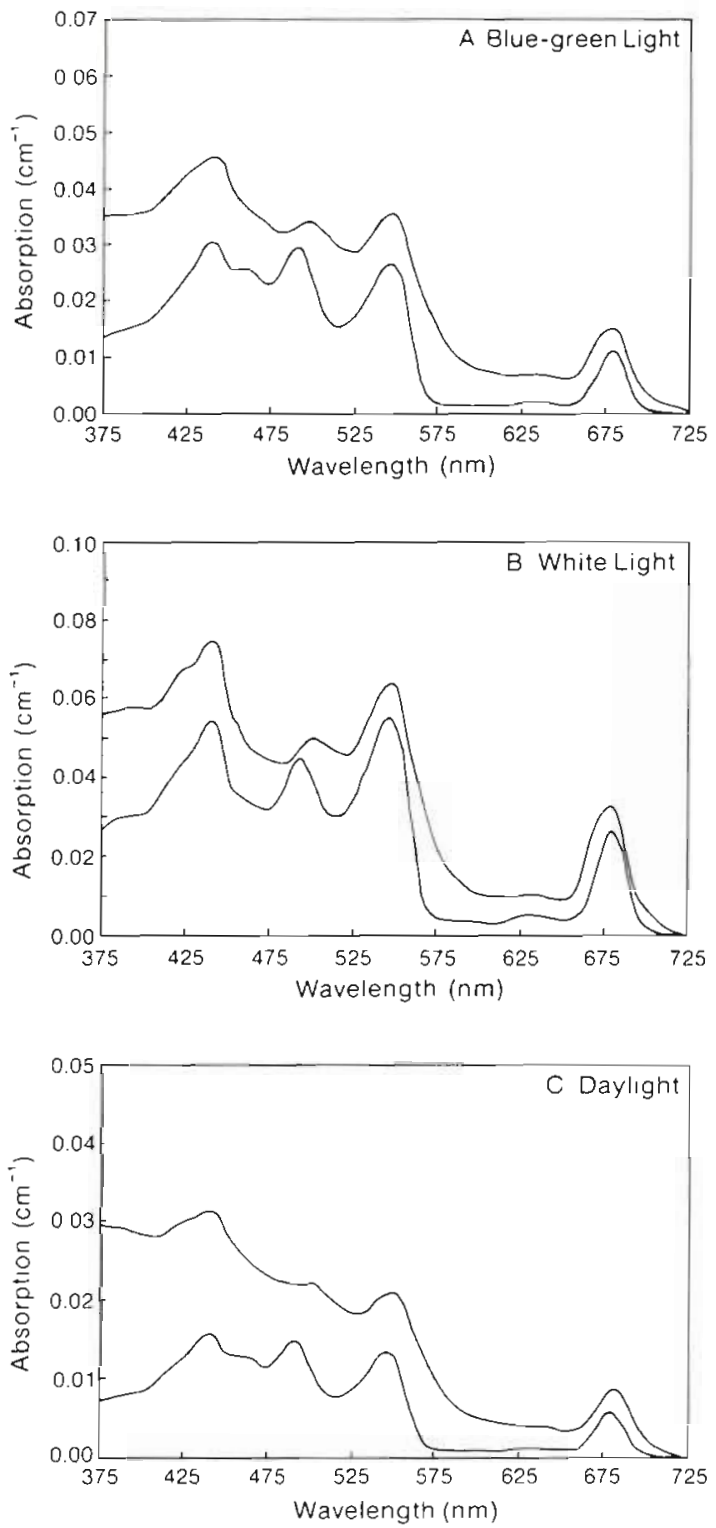

Fig. 3. Comparison of the directly measured (upper curves) and reconstructed (lower curves) absorption spectra $\left(\mathrm{cm}^{-1}\right.$. base 10) for Synechococcus grown under (A) blue-green light,

(B) white light and (C) daylight

measured and reconstructed absorption spectra (Fig. 4). Each of the resulting curves revealed a PEBrich phycoerythrin signature superimposed upon an exponentially decaying 'background' absorption spectrum which resembled that of particulate detritus (Iturriaga \& Siegel 1988, Bidigare et al. 1989). These background spectra (minus the phycoerythrin contributions) lacked any well defined peaks which might be attributable to photosynthetic pigments, including phycocyanin, with the possible exception of the small peaks near 440 and $675 \mathrm{~nm}$ (chlorophyll a). The chromophores responsible for these absorption spectra are
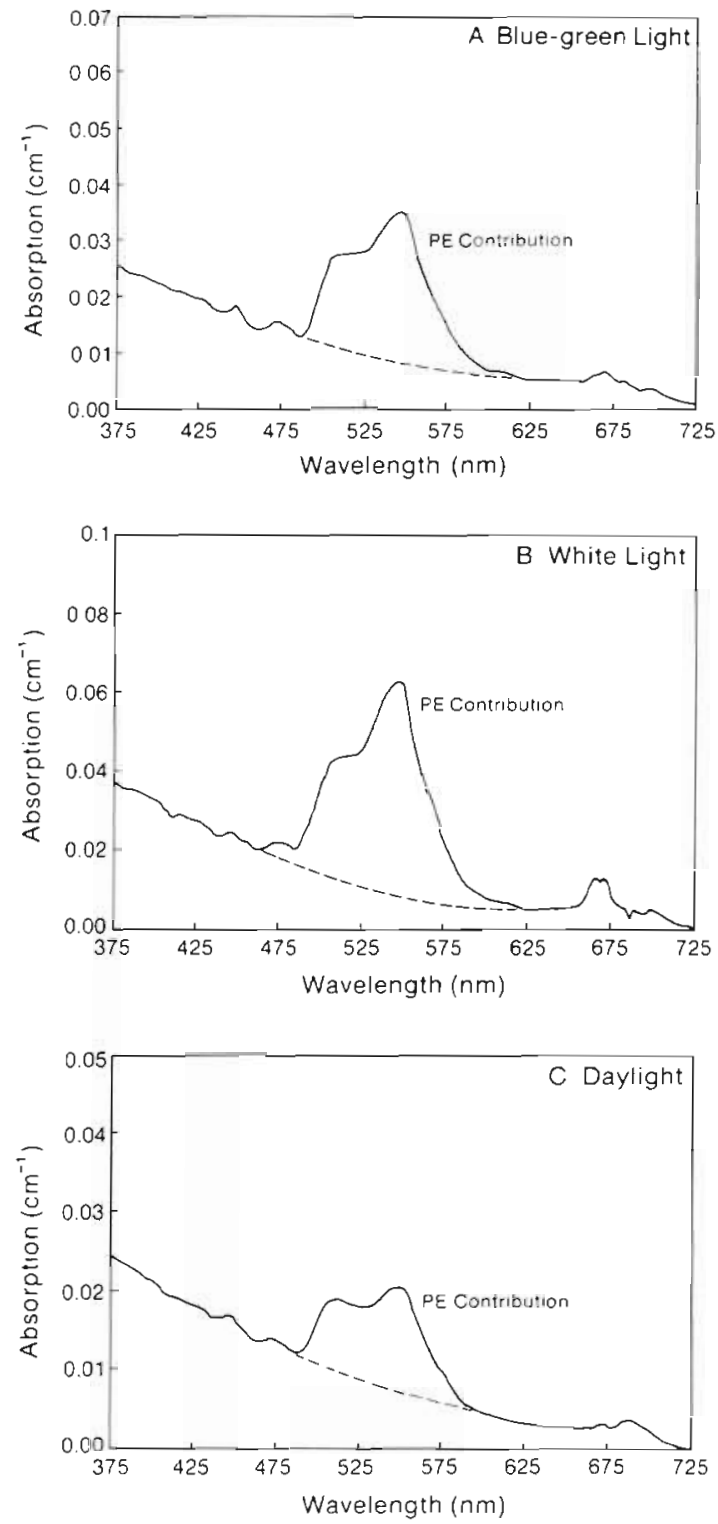

Fig. 4. Difference spectra calculated as the directly measured minus reconstructed absorption (chlorophyll a + zeaxanthin + $\beta$-carotene) spectra of Synechococcus grown under (A) bluegreen light, (B) white light and (C) daylight. The resulting phycoerythrin absorption signatures were used to calculate volume-and cell-based phycoerythrin concentrations for each growth condition (see text for details)

not known at this time, but we speculate that they may be related to the UV-absorbing compounds characteristic of certain blue-green algae (cf. Shibata 1969). After subtraction of the background absorption spectra, both the magnitude and shape of the directly-measured and reconstructed spectra agreed reasonably well. These results suggest that 'pigment packaging' effects are minimal in Synechococcus grown under these conditions (cf. Morel \& Bricaud 1986).

The chlorophyll a-specific absorption spectra calcu- 
lated for each growth condition are shown in Fig. 5 (upper curve in each panel), and possess several prominent absorption maxima corresponding to chlorophyll a (440 and $680 \mathrm{~nm})$ and phycoerythrin $(547 \mathrm{~nm})$. To assess the contribution of zeaxanthin to cellular absorption, volume-based zeaxanthin concentrations (Table 2) were multiplied by the specific absorption coefficients ( 375 to $725 \mathrm{~nm}$ ) estimated for zeaxanthin (Fig. 2) to yield a wavelength-dependent zeaxanthin absorption contribution. These values were then
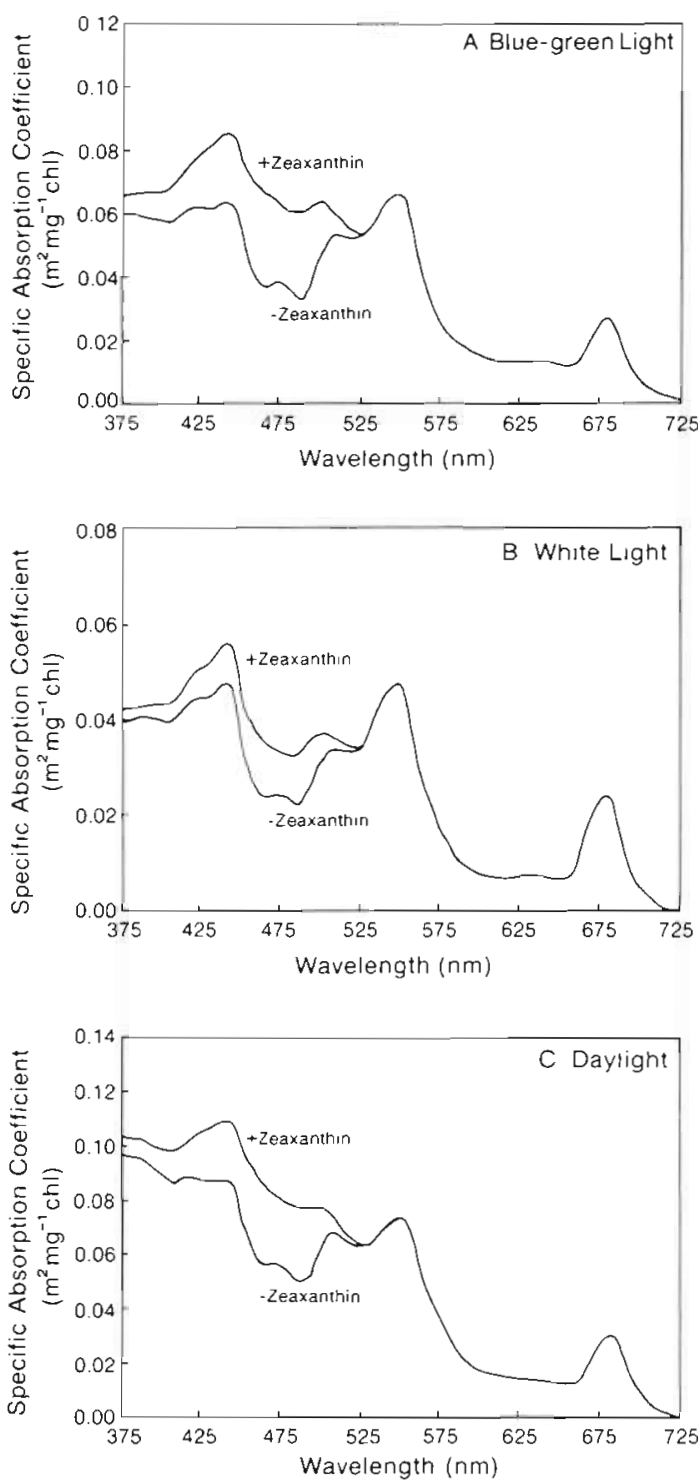

Fig. 5. Chlorophyll-specific absorption spectra $\left(\mathrm{m}^{2} \mathrm{mg}^{-1} \mathrm{Chl}\right.$, base e) for Synechococcus grown under (A) blue-green light, (B) white light and (C) daylight. The upper curves (+ zeaxanthin) were calculated by dividing the measured absorption spectra by the volume-based chlorophyll a concentrations determined for each culture. The lower curves (-zeaxanthin) represent the chlorophyll-specific absorption spectra minus the absorption contributions produced by zeaxanthin divided by volume-based chlorophyll a concentration and subtracted from the chlorophyll a-specific absorption to yield specific absorption coefficients minus the zeaxanthin contribution (Fig. 5, lower curve in each panel).

\section{Carbon action spectra and quantum yield}

Carbon action spectra $\left(\mathrm{mgC}\right.$ mgChl ${ }^{-1} \mathrm{~h}^{-1}\left[\mu \mathrm{Ein} \mathrm{m}^{-2}\right.$ $\mathrm{s}^{-1} \mathrm{j}^{-1}$ ) measured for Synechococcus grown under bluegreen light, white light and daylight are shown in Fig. 6. The shape and magnitude of these spectra are

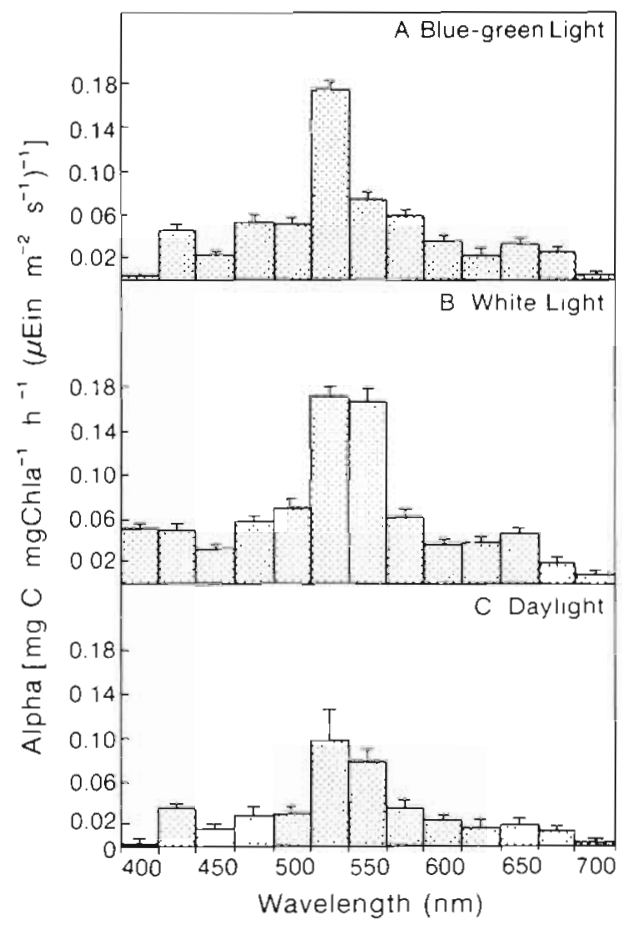

Fig. 6. Carbon action spectra $\left(\mathrm{mgC} \mathrm{mgChl}^{-1} \mathrm{~h}^{-1}\left(\mu \mathrm{Ein} \mathrm{m}^{-2}\right.\right.$ $\left.\mathrm{s}^{-1}\right)^{-1}$ ) for Synechococcus grown undor (A) blue-green light, $(B)$ white light and $(C)$ daylight. The error bars indicate \pm one standard error of the wavelength-dependent alpha estimate

similar to those reported by Lewis et al. (1986) and Boucher et al. (unpubl.) for the same strain of Synechococcus. Highest alpha values were measured between 525 and $550 \mathrm{~nm}$; they coincide with the spectral region where phycoerythrin absorption dominates. This is especially true for the white-light and daylight grown cells which displayed high alpha values in both the 525 and 550 wavebands, the latter of which corresponds to the relatively high outputs of the white fluorescent and daylight-filtered tungsten lamps in this spectral region (Fig. 1).

Highest quantum yields were measured between 525 and $650 \mathrm{~nm}$, indicating that phycobilins (phycoerythrin 
and phycocyanin) are important light harvesting pigments for photosynthetic carbon fixation in Synechococcus (Fig. 7). Similar results were reported by Lewis et al. (1988) for a natural population of Trichodesmium sp. which displayed an average quantum yield value of $0.086 \mathrm{molC} \mathrm{Ein}^{-1}$ between 475 and $650 \mathrm{~nm}$. The importance of phycoerythrin in driving

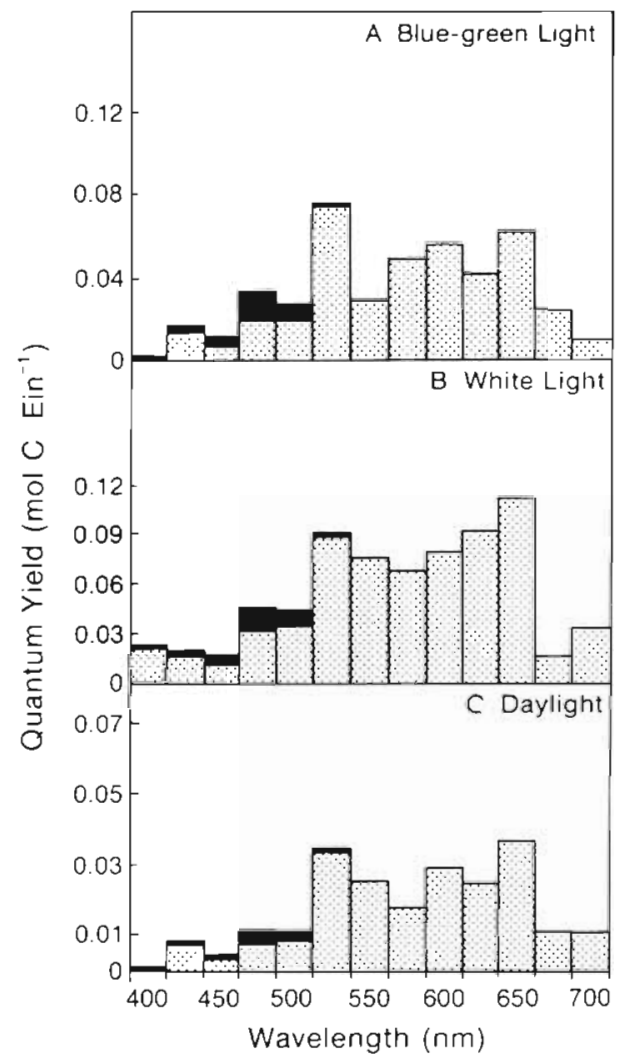

Fig. 7. Spectral quantum yield of photosynthesis (molC Ein $^{-1}$ ) for Synechococcus grown under (A) blue-green light, (B) white light and (C) daylight. Quantum yield values were calculated by rationing the carbon action spectra (Fig. 6) to the chlorophyll-specific absorption spectra (Fig. 5). The black bars indicate the magnitude of quantum yield reduction produced by non-photosynthetically active zeaxanthin

photosynthesis in Synechococcus was further investigated by computing rates of wavelength-dependent production, weighted by the photosynthetically available radiation for each culture condition (Fig. 8). Photosynthesis in the 525 and $550 \mathrm{~nm}$ wavebands accounted for 40,50 , and $60 \%$ of the total carbon fixed (400 to $700 \mathrm{~nm}$ wavebands) by Synechococcus grown under blue-green, white and daylight-filtered light.

Quantum yield values were also calculated without absorption contributions by zeaxanthin to assess the influence of this photosynthetically incompetent' carotenoid on the quantum yield of Synechococcus. A comparison of values measured between 425 and

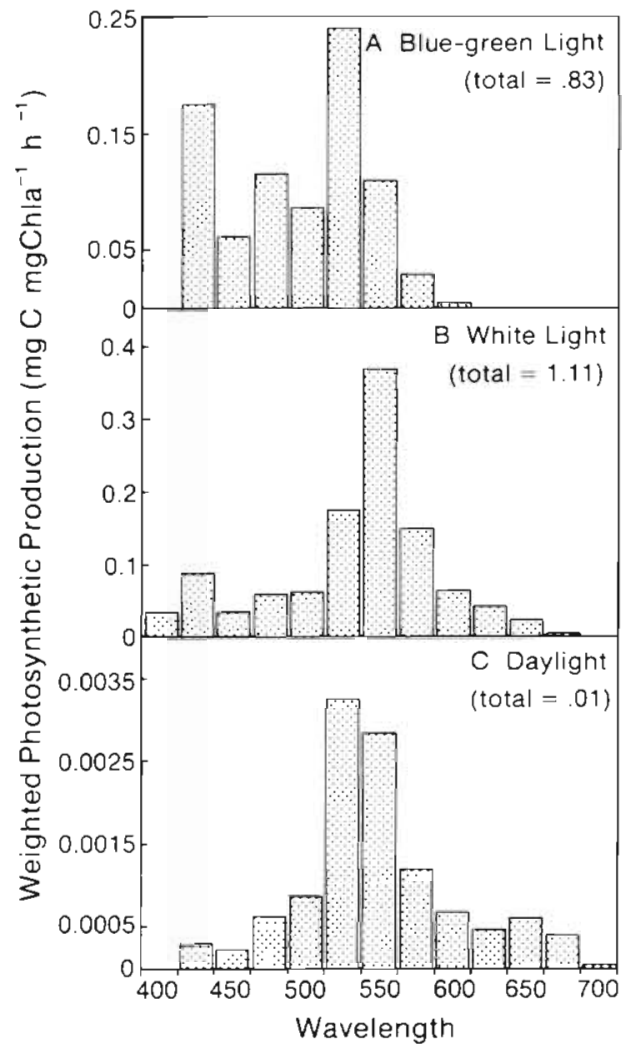

Fig. 8. Wavelength-dependent rates of production (mgC $\mathrm{mgChl} a^{-1} \mathrm{~h}^{-1}$ ) calculated for Synechococcus grown under (A) blue-green light, (B) white light and (C) daylight. Production rates were weighted by the photosynthetically available radiation measured for each culture condition (Fig. 1)

$500 \mathrm{~nm}(+/-$ zeaxanthin) indicates that zeaxanthin produces 20 to $40 \%$ reductions in photosynthetic quantum yield (Table 4). Furthermore, a direct comparison between white light grown cells and zeaxanthin-rich blue-green light grown cells reveals that the latter has 30 to $50 \%$ lower quantum yield values in the wavebands where zeaxanthin absorbs (425 to $500 \mathrm{~nm}$ ).

\section{DISCUSSION}

The use of conventional methods for investigating the physiological ecology of marine ultraphytoplankton has been limited by their small cellular dimensions, fragility and poor preservation properties. In the past decade, the routine use of sophisticated analytical techniques such as flow cytometry, spectral 'P vs I' incubations, high-performance liquid chromatography, single cell microphotometry and immunofluorescence has provided new insights into the classification, distributions and photoadaptive strategies of marine ultraphytoplankton. The application of these methods to laboratory cultures and natural populations has une- 
Table 4. Spectral quantum yield values $\left(\mathrm{mol} \mathrm{C} \cdot \operatorname{Ein}^{-1}, 425-500 \mathrm{~nm}\right.$ ) for Synechococcus grown under blue-green light, white light and daylight-filtered tungsten light. Quantum yield values were calculated by dividing the $\alpha_{\lambda}$ values by the corresponding measured chlorophyll-specific absorption (+zeaxanthin) and the measured chloropyhll-specific absorption minus zeaxanthin absorption contributions (-zeaxanthin)

\begin{tabular}{|c|c|c|c|}
\hline $\begin{array}{l}\text { Wavelength } \\
(\mathrm{nm})\end{array}$ & $\begin{array}{c}\text { Quantum yield o } \\
\text { + Zeaxanthin }\end{array}$ & $\begin{array}{l}\text { sis ( }\left(\text { mol C } \cdot \text { Ein }^{-1} \text { ) }\right. \\
\text {-Zeaxanthin }\end{array}$ & $\phi_{+z e a} / \phi_{-z e u}$ \\
\hline \multicolumn{4}{|l|}{ Blue-green light } \\
\hline 425 & 0.014 & 0.017 & 0.82 \\
\hline 450 & 0.007 & 0.011 & 0.64 \\
\hline 475 & 0.019 & 0.033 & 0.58 \\
\hline 500 & 0.019 & 0.027 & 0.70 \\
\hline \multicolumn{4}{|l|}{ White light } \\
\hline 425 & 0.018 & 0.021 & 0.86 \\
\hline 450 & 0.013 & 0.018 & 0.72 \\
\hline 475 & 0.033 & 0.047 & 0.70 \\
\hline 500 & 0.037 & 0.045 & 0.82 \\
\hline \multicolumn{4}{|l|}{ Daylight } \\
\hline 425 & 0.008 & 0.009 & 0.89 \\
\hline 450 & 0.004 & 0.005 & 0.80 \\
\hline 475 & 0.008 & 0.012 & 0.67 \\
\hline 500 & 0.009 & 0.012 & 0.75 \\
\hline
\end{tabular}

quivocally demonstrated that light quality is a major factor controlling the pigmentation, distributions and photosynthetic efficiencies of marine phytoplankton (Wood 1985, Glover et al. 1986a, b, Prézelin et al. 1986, Glover et al. 1987, Hooks 1987, Glover et al. 1988a, Bidigare et al. 1989, Prézelin et al. 1989).

The emerging picture resulting from such studies is that phytoplankton are heterogeneously distributed in the upper ocean and chromatically adapted for rapid growth in an environment whose light field is highly variable in both time and space, was well as spectral composition. It is now generally accepted that it is necessary to take into account (1) the intensity, spectral composition and angular distribution of light and (2) the wavelength-dependent absorption and photophysiological properties of phytoplankton to accurately model primary production rates in oceanic waters (Lewis et al. 1985b, Collins et al. 1986, Bidigare et al. 1987, Morel et al. 1987, Collins et al. 1988, Platt \& Sathyendranath 1988, Sathyendranath \& Platt 1988 , 1989, Smith et al. 1989). Thus, such models require knowledge of the functional linkages between the availability of spectral irradiance, absorption properties of the 'photosynthetically active' pigments and the efficiency at which absorbed light energy is used for carbon fixation (cf. Bidigare et al. 1987). Toward the objective of developing accurate production models, our laboratory studies have focused on these relationships in the major spectral types of marine phytoplankton, most notably the golden-brown, green and blue-green algae. The results obtained with a representative of the latter group, Synechococcus clone
WH 7803, are presented here and elsewhere (Boucher et al. unpubl.).

Variations in growth illumination quality produced significant differences in the chlorophyll a-specific absorption, photosynthetic efficiency and quantum yield of Synechococcus (Figs. 5 to 7). Light quality not only affected the magnitudes of these parameters, but their spectral dependencies as well. Chlorophyll aspecific absorption coefficients at $680 \mathrm{~nm}$, however, were similar and averaged $0.028 \pm 0.008 \mathrm{~m}^{-2} \mathrm{mg}(\mathrm{n}=$ 3). Absorption contributions by other cellular components were probably responsible for increasing the magnitude of this coefficient above the maximum 'unpackaged' value documented for chlorophyll a (0.0202 $\mathrm{m}^{-2} \mathrm{mg}$, cf. Haardt \& Maske 1987). In contrast, chlorophyll a-specific absorption coefficients at $440 \mathrm{~nm}$ varied by a factor of $2\left(0.06\right.$ to $0.11 \mathrm{~m}^{-2} \mathrm{mg}$, Fig. 5) and were dependent on variable absorption contributions by accessory pigments (zeaxanthin, $\beta$-carotene and phycoerythrin) and other cellular components.

Highest photosynthetic efficiencies $[\alpha(\lambda)]$ were measured at the blue-green to green wavelengths of light which dominate in the coastal waters where DC2-like Synechococcus are most common (Vernet et al. 1986, Bidigare unpubl., Boucher et al. unpubl.). Photosynthetic efficiencies were found to be highly wavelength dependent and up to 2-fold variations were observed between cultures at wavelengths corresponding to maximum phycoerythrin absorption (500 to $550 \mathrm{~nm}$ ).

Spectral quantum yield also displayed significant wavelength-dependent differences between the three experimental growth conditions (Fig. 7). Quantum 
yield values between 525 and $650 \mathrm{~nm}$ averaged 0.05 0.09 and 0.03 molC Ein ${ }^{-1}$ for Synechococcus grown under blue-green light, white light and daylight-filtered tungsten light, respectively (Fig. 7). These between-culture differences are probably growth ratedependent (i.e. nutrient-dependent uncoupling of photosynthetic efficiency; Boucher et al. unpubl.) and not attributable to enhancement effects since only minor variations in the phycoerythrin-to-chlorophyll a ratio were observed (Table 3 ). For Synechococcus cells grown under white light, quantum yeld values in this spectral region were close to the maximum value of 0.10 molC Ein ${ }^{-1}$. Quantum yield estimates for natural populations of Synechococcus spp. samples in the oligotrophic North Pacific Ocean, in comparison, averaged $0.08 \pm 0.03$ (Iturriaga \& Mitchell 1986), and fall within the range of values determined for the bluegreen and white light grown cells.

The low quantum yield values measured between 400 and $500 \mathrm{~nm}$ are in part attributable to the absorption of light energy by photosynthetically incompetent pigments. Boucher et al. (unpubl.) found that enhancement effects were greatest at $425 \mathrm{~nm}$ and that a quantum yield minium was still evident at the wavelengths where zeaxantin absorption contributions are greatest (425 to $500 \mathrm{~nm}$, Fig. 2). In addition, chlorophyll a excitation spectra performed with high-light grown Synechococcus clone WH 7803 also revealed no significant activity in the spectral region where this carotenoid absorbs (Kana et al. 1988). Results from this study indicate that zeaxanthin alone can produce a 20 to $40 \%$ reduction in quantum yield in this spectral region, and 30 to $60 \%$ reductions if absorption contributions by $\beta$-carotene are included.

There is increasing evidence which suggests that zeaxanthin functions as a photoprotective pigment in cyanobacteria (Paerl et al. 1983, Gieskes \& Kraay 1986, Kana et al. 1988) and higher plants (Demmig et al. 1987). Carotenoids function as photoprotectants by interacting in photochemically induced oxidation reactions which occur in the presence of high light (Type I reactions) or high light and oxygen (Type II reactions). Specifically, carotenoids are capable of quenching (1) the triplet state of photosensitizing molecules; (2) singlet oxygen; and (3) free radical intermediates, all of which are potentially destructive (Rau 1988).

For Synechococcus clone WH7803, the ratio of zeaxanthin-to-chlorophyll a has been shown to increase with increasing growth irradiance (Kana et al. 1988). Kana et al. (1988), however, found that cellular zeaxanthin concentration remained constant over a wide rage of white fluorescent growth irradiances and that decreases in cellular chlorophyll a at high growth irradiances were responsible for elevated zeaxanthinto-chlorophyll a ratios. In this study, blue-green light grown Synechococcus cells had a $\sim 2$-fold higher zeaxanthin content than those grown under white light or daylight growth illuminations. These results indicate that cellular zeaxanthin content is not an implicit constant and its concentration is dependent on light quality alone and/or the irradiance level of specific bluegreen wavebands.

In conclusion, we have demonstrated that light quality has a marked effect on the spectral absorption properties and quantum yield of Synechococcus clone WH 7803. For this reason, physiological experiments should be conducted with cultures pre-adapted to the light conditions characteristic of the environment in which they were isolated. Wavelength-dependent variations in quantum yield can, in part, be explained by (1) differences in pigmentation resulting from photoadaptive responses to spectral irradiances and (2) an energy imbalance in photosynthetically absorbed light distribution between PSI and PSII (cf. Boucher et al. unpubl.). To minimize this variability for use in biooptical models, we recommend that spectral quantum yield values for cultures and natural phytoplankton populations be calculated from (1) carbon action spectra determined under 'enhanced' conditions when possible and (2) phytoplankton absorption spectra estimated using spectral reconstruction techniques without absorption contributions by chromophores (e.g photosynthetically incompetent carotenoids, particulate detrital matter) which are inefficient in photosynthetic energy transfer.

Acknowledgements. This research was supported by N.S.F. grants OCE 88-13727 (RRB) and OCE 88-00099 (BBP), and O.N.R contract N00014-86-C-0379 (RRB). Special thanks are given to Norman Nelson for measuring the spectral outputs of the lamps and filters.

\section{LITERATURE CITED}

Alberte, R. S. Wood, A. M., Kursar, T A., Guillard, R. R. L. (1984). Novel phycoerythrins in marine Synechococcus spp. Plant Physiol. 75: 732-739

Barlow, R. G., Alberte, R. S. (1985). Photosynthetic characteristics of phycoerythrin-containing manne Synechococcus spp. I. Responses to growth photon flux density. Mar Biol. 86: 63-74

Bidigare, R. R. (1989). Photosynthetic pigment composition of the brown tide alga: Unique chlorophyll and carotenoid derivatives. In: Cosper, E., Carpenter, E. J., Bricelj, M. (eds.) Lecture notes on coastal and estuarine studies. Springer-Verlag, New York (in press)

Bidigare, R. R., Morrow, J. H., Kiefer, D. A. (1989). Derivative analysis of spectral absorption by photosynthetic pigments in the western Sargasso Sea. J. mar. Res. 47: 323-341

Bidigare, R. R. Smith, R. C., Baker, K. S., Marra, J. (1987). Oceanic primary production estumates from measurements of spectral irradiance and pigment concentrations. Global biogeochem. Cycles 1. 171-186 
Campbell, L., Iturriaga, R. (1988). Identification of Synechococcus spp. in the Sargasso Sea by immunofluorescence and fluorescence excitation spectra performed on individual cells. Limnol. Oceanogr 33: 1196-1201

Collins, D. J., Booth, C. R., Davis, C. O., Kiefer, D. A., Stallings, C. (1988). A model of the photosynthetically available and usable irradiance in the sea. Proceedings of Ocean Optrcs IX. Society of Photo-Optical Instrumentation Engineers, Bellingham, WA. (SPIE) 925: 87-100

Collins, D. J., Kiefer, D. A., SooHoo, J. B., Stallings, C., Yang, W. (1986). A model of satellite remote sensing for the measurement of primary production in the ocean. Proceedings of Ocean Optics VIII. Society of Photo-Optical Instrumentation Engineers, Bellingham, WA (SPIE) 637: 335-348

Cuhel, R. L., Waterbury, J. B. (1984). Biochemical composition and short term nutrient incorporation patterns in a unicellular marine cyanobacterium, Synechococcus (WH7803). Limnol. Oceanogr. 29: 370-374

Davies, B. H. (1976). Carotenoids. In: Goodwin, T. W. (ed.) Chemistry and biochemistry of plant pigments. Academic Press, London, p. 38-165

Demmig, B., Winter, K., Kruger, A., Czygan, F. (1987). Photoinhibition and zeaxanthin formation in intact leaves. Plant Physiol. 84: 218-224

Gieskes, W W C., Kraay, G. W. (1986). Floristic and physiological differences between the shallow and the deep nanophytoplankton community in the euphotic zone of the open tropical Atlantic revealed by HPLC analysis of pigments. Mar. Biol. 91: 567-576

Glover, H. E. (1985). The physiology and ecology of the marine cyanobacterial genus Synechococcus. In: Jannasch, H. W. Williams, P. J. LeB. (eds.) Advances in aquatic microbiology. Academic Press, London. p. 49-107

Glover, H. E., Campbell, L., Prézelin, B. B. (1986a). Contribution of Synechococcus spp. to size-fractioned primary productivity in three water masses in the Northwest Atlantic Ocean. Mar. Biol. 91: 193-203

Glover, H. E., Keller, M. D., Guillard, R. R. L. (1986b). Light quality and oceanic ultraphytoplankters. Nature, Lond. 319: $142-243$

Glover, H. E., Keller, M. D., Spinrad, R. W (1987). The effects of light quality and intensity on photosynthesis and growth of marine eukaryotic and prokaryotic clones. J. exp. mar. Biol. Ecol. 105: 137-159

Glover, H. E., Prézelin, B. B., Campbell, L., Wyman, M. (1988a). Pico- and ultraplankton Sargasso Sea communities: Variability and comparative distributions of Synechococcus spp. and algae. Mar. Ecol. Prog. Ser. 49: $127-139$

Glover, H. E., Prézelin, B. B., Campbell, L., Wyman, M., Garside, C. (1988b). A nitrate-dependent Synechococcus bloom in surface Sargasso Sea water. Nature, Lond. 331: $161-163$

Glover, H. E., Smith, A. E., Shapiro, L. (1985). Diurnal variations in photosynthetic rates: comparisons of ultraphytoplankton with a larger phytoplankton size fraction. J. Plankton Res. 7: 519-535

Guillard, R. R. L., Ryther, J. H. (1962). Studies of marine phytoplanktonic diatoms. I. Cyclotella nana Husdet and Detonula confervacea. Gran. Can. J. Microbiol. 8: 229-239

Guillard, R. R. L., Murphy, L. S., Foss, P., Liaaen-Jensen, S. (1985). Synechococcus spp. as likely zeaxanthin-dominant ultraplankton in the North Atlantic. Limnol. Oceanogr. 30: $412-414$

Haardt, H., Maske, H. (1987). Specific in vivo absorption coefficients of chlorophyll a at $675 \mathrm{~nm}$. Limnol. Oceanogr 32: $608-619$
Hooks, C. E. (1987). The influence of light intensity and quality on the growth, size, and pigment composition of select ultraphytoplankters. M. S. thesis, Texas A \& M University, College Station, Texas

Iturriaga, R., Marra, J. (1988). Temporal and spatial variability of chroococcoid cyanobacteria Synechococcus spp. specific growth rates and their contribution to primary production in the Sargasso Sea. Mar Ecol. Prog. Ser 44: $175-181$

Iturriaga, R., Mitchell, B. G. (1986). Chroococcoid cyanobacteria: A significant component in the food web dynamics of the open ocean. Mar. Ecol. Prog. Ser 28: 291-297

Iturriaga, R., Siegel, D. A. (1988). Discrimination of the absorption properties of parine particulates using a microphotometric technique. Proceedings of Ocean Optics IX. Society of Photo-Optical Instrumentation Engineers, Bellingham, WA (SPIE) 925: 277-287

Jeffrey, S. W. (1981). An improved thin-layer chromatographic technique for marine phytoplankton pigments. Limnol. Oceanogr. 16: 191-197

Jeffrey, S. W., Humphrey, G. F. (1975). New spectrophotometric equations for determining chlorophylls $a, b, c$ in higher plants, algae, and natural phytoplankton. Biochem. Physiol. Acta 167: 191-194

Kana, T M., Glibert, P. M. (1987). Effect of irradiances up to $2000 \mu \mathrm{E} \mathrm{m}^{-2} \mathrm{~s}^{-1}$ on marine Synechococcus WH7803. II. Photosynthetic responses and mechanisms. Deep Sea Res. 34: $497-516$

Kana, T. M., Glibert, P. M., Goericke, R., Welschmeyer, N. A. (1988). Zeaxanthin and $\beta$-carotene in Synechococcus WH7803 respond differently to irradiance. Limnol. Oceanogr. 33: 1623-1627

Kilpatrick, K. A. (1985). The development of a method to measure marine cyanobacterial phycoerythrin extracted in solvents. M. S. thesis, Texas A \& M University, College Station, Texas

Lewis, M. R., Ulloa, O., Platt, T (1988). Photosynthetic action, absorption, and quantum yield spectra for a natural population of Oscillatoria in the North Atlantic. Limnol. Oceanogr. 33: 92-98

Lewis, M. R., Warnnock, R. E., Irwin, B., Platt, T. (1985a). Measuring photosynthetic action spectra of natural phytoplankton populations. J. Phycol 21: 310-315

Lewis, M. R., Warnock, R. E., Platt, T. (1985b). Absorption and photosynthetic action spectra for natural phytoplankton populations: implications for production in the open ocean. Limnol. Oceanogr. 30: 794-806

Lewis, M. R., Warnock, R. E., Plat:, T (1986). Photosynthetic response of marine phytoplankton at low photon flux. In Platt, T., Li, W. K. W. (eds.) Photosynthetic picoplankton. Can. Bull. Fish. aquat. Sciences 214: 235-250

Mann, J. E., Myers, J. (1968). On pigments, growth, and photosynthesis of Phaeodactylum tricornutum. J. Phycol. 4: 349-355

Mantoura, R. F. C., Llewellyn, C. A. (1983). The rapid determination of algal chlorophyll and carotenoid pigments and their breakdown products in natural waters by reversephase high-performance liquid chromatography. Analytica chim. Acta 151, 297-314

Morel, A., Bricaud, A. (1986). Inherent optical properties of algal cells including picoplankton: Theoretical and experimental results. In: Platt, T., Li, W. K. W. (eds.) Photosynthetic picoplankton. Can. Bull. Fish. Aquat. Sci. 214: 521-559

Morel, A., Lazzara, L., Gostan, J. (1987). Growth rate and quantum yield time response for a diatom to changing irradiances (energy and color). Limnol. Oceanogr. 32 1066-1084 
Murphy, L. S. Haugen, E. (1985). The distribution and abundance of phototrophic picoplankton in the North Atlantic. Limnol. Oceanogr. 30: 47-58

Olson, R. J., Chisholm, S. W., Zettler, Armbrust, E. V. (1988). Analysis of Synechococcus pigment types in the sea using single and dual beam flow cytometry. Deep Sea Res. 35: 425-440

Ong, L. J., Glazer, A. N., Waterbury, J. B. (1984). An unusual phycoerythrin from a marine cyanobacterium Science 224: 80-83

Paerl, H. W., Tucker, J., Bland, P. T (1983). Carotenoid enhancement and its role in maintaining blue-green algal (Microcystis aeruginosa) surface blooms Limnol. Oceanogr. 28: 847-857

Platt, T., Sathyendranath, S. (1988). Oceanic primary production: Estimation by remote sensing at local and regional scales. Science 241: 1613-1620

Prézelin, B. B., Glover, H. E., Ver Hoven, B., Steinberg, D., Matlick, H. A, Schofield, O., Nelson, N., Wyman, M. Campbell, L. (1989). Blue-green light effects on light-limited rates of photosynthesis: relationship to pigmentation and productivity estimates for Synechococcus populations from the Sargasso Sea. Mar. Ecol. Prog. Ser. 54: 121-136

Prézelin, B. B., Putt, M., Glover, H. E. (1986). Diurnal patterns in photosynthetic capacity and depth-dependent photosynthesis-irradiance relationships in Synechococcus spp. and larger phytoplankton in thress water masses in the Northwest Atlantic Ocean. Mar. Biol. 91: 205-217

Rau, W. (1988). Functions of carotenoids other than in photosynthesis. In: Goodwin, $T$. W. (ed.) Plant pigments. Academic Press, London, p. 231-255

This article was submitted to the editor.
Sathyendranth, S., Platt, T. (1988). The spectral irradiance field at the surface and the interior of the ocean: a model for applucations in oceanography and remote sensing. J Geophys. Res. 93: 9270-9280

Sathyendranth, S., Platt, T (1989). Computation of aquatic primary production: Extended formalism to include effect of angular and spectral distribution of light. Limnol. Oceanogr 34: 188-198

Shibata, K. (1969). Pigments and a UV-absorbing substance in corals and blue-green alga living in the Great Barrier Reet Plant Cell Physiol. 10: 325-335

Smith, R. C., Prézelin, B. B., Bidigare, R. R., Baker, K. S. (1989). Bio-optical modeling of photosynthetic production in coastal waters. Limnol. Oceanogr. (in press)

Strickland, J. D. H., Parsons, T R. (1972). A practical handbook of seawater analysis, 2nd edn. Bull Fish. Res. Bd Can. 167

Vernet, M. Mitchell, B. G., Holm-Hansen, O. (1986). Phycoerythrin in plankton off Scripps Pier. EOS 67: Abstract L022B-02

Wood, A. M. (1985). Adaptation of photosynthetic apparatus of marine ultraphytoplankton to natural light fields. Nature Lond. 316: 253-255

Wood, A. M., Horan, P. K., Muirhead, K., Phinney, D. A. Yentsch, C. M., Waterbury, J. B. (1985). Discrimination between types of pigments in marine Synechococcus spp. by scanning spectroscopy, epifluorescence microscopy, and flow cytometry. Limnol. Oceanogr. 30: 1303-1315

Wyman, M., Gregory, R. P. F., Carr, N. G. (1985). Novel role for phycoerythrin in a marine cyanobacterium Synechococcus strain DC-2. Science 230: 818-820

Manuscript first received: April 29, 1989

Accepted: May 9, 1989 